\title{
Entre escolas e famílias: revelações dos deveres de casa
}

\author{
Tânia de Freitas Resende \\ Universidade Federal de Minas Gerais, Belo Horizonte-MG, Brasil
}

\begin{abstract}
Resumo: Neste estudo investigaram-se as práticas e concepções relativas ao dever de casa, em camadas populares e nas camadas médias, buscando desvelar aspectos do processo educacional referentes às relações família-escola e ao currículo escolar. Os participantes da pesquisa foram professores, alunos e pais de três turmas de $3^{\text {a }}$ série do ensino fundamental, de duas escolas privadas e uma pública. Realizaram-se observações em sala de aula, aplicou-se um questionário aos pais dos alunos e foram feitas entrevistas com os profissionais e com dez pais de cada escola. A análise dos dados revelou: (a) um consenso entre as famílias investigadas quanto à importância dos deveres de casa e de seu acompanhamento pelos pais do aluno; (b) as desigualdades de condições familiares para esse acompanhamento, bem como as desigualdades de ofertas educacionais das escolas. Tais resultados evidenciam a complexidade escondida nas práticas aparentemente banais ligadas aos deveres de casa.
\end{abstract}

Palavras-chave: Lição de casa. Relações pais-escola. Currículo.

\section{Between schools and families: homework revealed}

\begin{abstract}
The practices and conceptions related to homework in low income and middle classes were investigated in this study. It aimed to unveil aspects of the educational process concerned to the family-school relation and school curricula. The research participants were teachers, students and parents of three $3^{\text {rd }}$ grade classes from two private schools and one public school. The classes were observed, a questionnaire was applied to the students' parents, and professionals and ten parents from each school were interviewed. The data analysis revealed: (a) consensus was reached regarding the importance of the homework among the investigated families; (b) unequal family conditions for assisting this task and unequal educational support schools offer. These results evidence the complexity hidden in the apparently unimportant practices related to homework.
\end{abstract}

Keywords: Homework. Parent-school relationship. Curriculum.

\section{Entre escuelas y familias: revelaciones de las tareas en casa}

Resumen: Cuesto estudio investigo las prácticas y concepciones relativas al los deberes de casa, en camadas populares y en las clases medias, buscándose por medio de ellas, revelar aspectos del proceso educacional referente a las relaciones familia-escuela y al currículo escolar .Los participantes de la investigación fueron profesores, alumnos y padres de tres salas de $3^{\circ}$ grado de la primaria, de dos escuelas privadas y una pública. Se realizaron observaciones en la sala de aula, se aplicó un cuestionario a los padres de los alumnos y se realizaron entrevistas con los profesionales y con diez padres de cada escuela. El análisis de los datos reveló: (a) un consenso entre las familias investigadas en cuanto a la importancia de los deberes de casa y del acompañamiento de los padres; (b) las desigualdades de las condiciones familiares para ese acompañamiento, así como las desigualdades de ofertas educacionales de las escuelas. Tales resultados evidencian la complejidad escondida en las prácticas aparentemente banales ligadas a los deberes de casa.

Palabras claves: Tareas en casa. Relaciones padre-escuela. Curriculum. 


\section{Introdução}

Neste artigo apresentam-se alguns dos resultados obtidos em uma investigação que tomou como objeto as concepções e práticas em relação ao dever de casa, focalizando escolas que atendem crianças de camadas médias e de camadas populares e suas famílias.

O dever de casa é aqui considerado como toda atividade pedagógica elaborada e proposta por professores, destinada ao trabalho dos alunos fora do período regular de aulas (Franco, 2002). Inclui, assim, exercícios escritos, pesquisas, resolução de problemas, atividades práticas, dentre outras. Dessa forma constitui, por um lado, um dos dispositivos curriculares por meio dos quais a escola concretiza seu trabalho pedagógico. Para Henriques (2007), trata-se de uma das rotinas curriculares instituídas pela escola e tacitamente aceitas pelos atores sociais nela envolvidos. Por outro lado, o dever de casa permeia também o cotidiano das famílias, redefinindo, em certa medida, o lar como uma extensão da sala de aula e constituindo, para alguns autores, o principal meio de interação família-escola (Carvalho, 2001).

Entretanto, embora tradicional como prática curricular, importante no cotidiano das relações família-escola e freqüentemente polemizado no âmbito do senso comum e de publicações voltadas para o grande público ou para professores da educação básica, o dever de casa tem sido pouco focalizado nas pesquisas científicas em educação (Carvalho, 2006; Glasman, 2005). Paula (2000) faz um levantamento de publicações que tratam do dever de casa, observando um crescimento, a partir das décadas de 1980-1990, do número de publicações sobre a temática, tanto voltadas para professores quanto para o grande público. Constata também, pelos próprios títulos das publicações, o caráter polêmico do tema. Carvalho (2004) verifica que ele aparece mais freqüentemente como um tópico periférico em análises sobre rendimento acadêmico e relação família-escola, sem que seja tomado, em si, como objeto de investigação.
Neste artigo, parte-se do pressuposto de que, para além de suas vinculações com o desempenho acadêmico, as práticas e concepções relativas ao dever de casa ganham relevância, sobretudo, pelo fato de que podem "espelhar" diversos aspectos do processo educacional, dentre eles o currículo escolar e as relações família-escola. Assim, buscou-se investigá-las, tomando-as como componentes de um conjunto mais amplo de formas de construção da escolaridade em diferentes meios sociais. Para tanto, a pesquisa fundamentou-se em contribuições oriundas da sociologia das relações família-escola e da sociologia do currículo, dois campos de estudo que vêm despertando crescente interesse no Brasil (Moreira, 2001; Nogueira, Romanelli, \& Zago, 2000).

A sociologia das relações família-escola configurou-se como um campo de estudos específico, dentro da Sociologia da Educação, a partir da década de 80 do último século. Segundo Nogueira (1998), contribuíram para sua constituição tanto mudanças na conjuntura teórica da Sociologia da Educação quanto transformações no âmbito da família e das instituições de ensino, as quais resultaram em uma imbricação crescente entre essas duas instâncias educativas. Tais transformações se fizeram acompanhar de políticas educacionais que buscavam incentivar a parceria família-escola, algumas dessas políticas preconizando, explicitamente, a prática dos deveres de casa como fator de eficácia escolar (Carvalho, 2000).

Boa parte do esforço teórico empreendido pela sociologia das relações família-escola tem sido no sentido de compreender as relações que mais caracteristicamente se estabelecem entre famílias pertencentes a diferentes classes sociais, ou frações de classe, e a escola (Nogueira, 1991). Pode-se afirmar que a investigação das diferentes práticas, estilos e comportamentos dos grupos familiares em relação ao universo escolar tem permitido compreender melhor a constituição de distintas trajetórias escolares ou formas de escolaridade. No Brasil, uma amostra desse tipo de abordagem está reunida nas coletâneas organizadas por Nogueira e cols. (2000) e por Almeida e Nogueira (2002). 
É no contexto desse quadro de estudos que se localiza um dos eixos da presente pesquisa. Parte-se do fato de que o dever de casa é a atividade escolar que mais diretamente envolve a família, especialmente quando se trata dos anos iniciais de escolarização. Sendo assim, objetiva-se, pela investigação das concepções e práticas familiares em relação ao dever de casa, em diferentes meios sociais, desvelar alguns significados da escolaridade para as famílias e compreender melhor suas relações com o universo escolar.

Ao mesmo tempo, considerando o dever de casa como um dispositivo curricular, busca-se, também, investigar as formas como é proposto e explorado nas escolas, bem como as concepções dos professores em relação a ele. Assume-se, nesse caso, uma vinculação com os estudos sociológicos que vêm, desde as últimas décadas do século XX, procurando desenvolver uma análise crítica dos processos de construção social do currículo (Moreira \& Silva, 1999). Focaliza-se especialmente o currículo em ação, ou seja, as práticas ou textos curriculares que se efetivam no espaço escolar, por meio de um processo de negociação entre os atores educativos (especialmente professor e alunos) a partir do currículo formal ou prescrito (Perrenoud, 1995). Considera-se, nessa perspectiva, o dever de casa como prática ou texto curricular que, organizado a partir de saberes prescritos no currículo formal e de procedimentos ou atividades tipicamente escolares, somente se concretiza por meio da ação de professores, alunos e famílias, dos significados que estes lhe atribuem, a partir de suas próprias lógicas como atores sociais, e das estratégias que desenvolvem em relação a ele.

Moreira (2001, p. 46), analisando o campo do currículo no Brasil, chama a atenção para a importância de se incrementar "investigações que priorizem as ações que se passam nas escolas, visando compreendê-las mais profundamente". A compreensão das ações ligadas aos deveres de casa, tomadas como componentes do currículo escolar que podem espelhar aspectos da organização curricular mais geral, constitui o segundo eixo de sustentação deste estudo.

\section{Método}

O marco teórico a partir do qual se construiu o objeto da presente pesquisa supõe o desenvolvimento de uma investigação de caráter microssociológico, voltada para a descrição de práticas e estratégias dos atores, bem como para a análise de suas concepções e perspectivas em relação ao assunto em questão. Implica, assim, em um enfoque predominantemente qualitativo, no sentido de que busca analisar os significados de comportamentos ou eventos a partir da compreensão de um conjunto de inter-relações que emergem do contexto, extraindo progressivamente categorias de análise, a partir do processo de coleta de dados, ao invés de trabalhar com categorias definidas a priori (Alves-Mazzotti \& Gewandsznajder, 1998).

\section{Participantes}

Selecionaram-se para a pesquisa três turmas da $3^{\mathrm{a}}$ série do ensino fundamental, sendo uma turma formada por crianças das camadas populares e as outras duas por crianças das camadas médias. Participaram da investigação os alunos, seus professores e seus pais/mães.

O enfoque nas séries iniciais do ensino fundamental se justifica por tratar-se de um momento da escolaridade no qual, em geral, os deveres de casa têm um papel significativo no desenvolvimento do currículo, ao mesmo tempo em que é também o período no qual a ajuda parental atinge seu nível mais alto (Franco, 2002). Por sua vez, a $3^{\mathrm{a}}$ série foi considerada como momento intermediário no qual, ao lado da participação parental na vida escolar dos filhos, a criança já tem certa autonomia para a realização dos deveres.

Quanto à definição do universo a ser investigado como referente às camadas populares e camadas médias, sabe-se que, como afirma Nogueira (1995), a tentativa de estabelecer linhas de demarcação entre camadas médias, elites e classes populares é problemática, especialmente considerando a grande heterogeneidade interna das chamadas camadas médias. No caso da presente pesquisa, buscou-se 
definir dois meios sociais contrastantes quanto às condições materiais e simbólicas que pudessem influenciar no acompanhamento e apoio parental à vida escolar dos filhos. Sendo assim, para assegurar o enfoque nas camadas populares, procurou-se encontrar uma escola em que as crianças fossem oriundas, em sua maioria, de famílias com baixo nível de renda e de escolaridade e nas quais predominassem ocupações manuais dos pais. Para isso, foram feitos contatos com escolas públicas que atendiam crianças moradoras de aglomerados de Belo Horizonte-MG. Já no caso das camadas médias, a intenção foi a de privilegiar, dentro desse universo, as frações que Quadros (1991) qualifica como superiores, envolvendo famílias que se caracterizassem por nível de renda relativamente elevado e pela posse de capital cultural. Esse foi considerado, nos termos de Bourdieu (1998), como “poder advindo da produção, da posse, da apreciação ou do consumo de bens culturais socialmente dominantes" (Nogueira \& Nogueira, 2004, p. 40), podendo incluir credenciais escolares, bens culturais, conhecimentos, estratégias, disposições e valores, utilizados na vida social como fonte de distinção e poder (Setton, 2005). No caso desta pesquisa, considerou-se basicamente, como critério para caracterização da posse de capital cultural, a escolaridade de nível superior e as ocupações correspondentes. Para chegar a turmas escolares cujas famílias reunissem tais condições, foram feitos contatos com escolas privadas consideradas de prestígio na cidade, que tendem a concentrar esse tipo de público.

Tendo em vista os critérios acima apresentados, selecionaram-se três escolas de Belo HorizonteMG, dois colégios privados, de prestígio significativo na comunidade, que atendem a alunos de camadas médias (Colégios Lua e Estrela), e uma escola pública estadual, com alunos de camadas populares, moradores de um dos maiores aglomerados da cidade (Escola Sol). Cabe ressaltar que os nomes das escolas são fictícios.

Os dados coletados durante a pesquisa permitiram confirmar o perfil desejado das famílias, descrito no parágrafo anterior. Na Escola Sol, a maioria dos pais e mães (77 e $82 \%$, respectivamente), cursou apenas o ensino fundamental, incompleto em boa parte dos casos (44\% dos pais e $30 \%$ das mães cursaram apenas até a $4^{\mathrm{a}}$ série ou menos). Predominam largamente, nesse universo, as ocupações urbanas nãoqualificadas (Pastore \& Silva, 2000), como servente de pedreiro, faxineiro, porteiro, vigia e outros (para os pais), e empregadas domésticas, faxineiras, ajudantes de serviços gerais (caso das mães). Entretanto, deve-se ressaltar que, apesar do claro pertencimento às camadas populares, o grupo de famílias que respondeu aos questionários e, principalmente, aquele que participou das entrevistas, na Escola Sol, parece apresentar, em sua maior parte, um patamar mínimo de estabilidade e segurança material, geralmente assegurado pelo trabalho dos dois genitores. Em conformidade com o que aponta De Queiroz (1981), em seu estudo sobre famílias populares urbanas na França, essa situação parece permitir, no caso das famílias investigadas na Escola Sol, um certo envolvimento com a vida escolar dos filhos, o qual o autor não verificou entre grupos submetidos a uma vulnerabilidade econômica mais severa.

Com relação às Escolas Lua e Estrela, predominam os pais e mães com ensino superior ou pósgraduação (73\% dos pais e $66 \%$ das mães na Escola Estrela; $85 \%$ dos pais e $79 \%$ das mães na Escola Lua), havendo, na geração dos avós, porcentagens significativas de acesso ao ensino superior ou, pelo menos, ao ensino médio. A profissão dos pais e mães corresponde a esse alto nível de escolaridade, predominando as ocupações de nível superior: engenheiros, médicos, advogados, funcionários públicos de nível superior, analistas, administradores, dentre outros.

\section{Procedimentos}

$\mathrm{Na}$ primeira etapa da pesquisa (entre março e dezembro de 2004), realizaram-se observações sistemáticas nas três turmas investigadas (aproximadamente dois meses em cada escola), envolvendo situações de aula, de recreio, reuniões de pais. Realizaram-se, ainda, entrevistas com a(s) professora(s) 
regente(s) de cada turma e com a coordenação pedagógica de cada escola.

$\mathrm{Na}$ segunda etapa da investigação ( $1^{\circ}$ semestre de 2005), os procedimentos adotados foram a aplicação de questionários e a realização de entrevistas com mães e/ou pais dos alunos. Os questionários, enviados por meio dos alunos, obtiveram os seguintes índices de resposta: $55 \%$ e $51 \%$ nas duas escolas privadas e $66 \%$ na escola pública. Foram respondidos predominantemente pelas mães dos alunos (72\% dos questionários na escola Sol, $79 \%$ na Estrela e 90\% na Lua); em proporção bem menor, pelos pais ou ainda, em pouquíssimos casos (média de $4 \%$ em cada escola), por outros adultos (avô, empregada doméstica, irmã, dentre outros).

As entrevistas, de caráter semi-diretivo, envolveram dez famílias de cada estabelecimento, selecionadas a partir das respostas ao questionário, de acordo com critérios que buscavam cobrir a maior variedade possível de perfis familiares. Também nesse caso predominaram as mães, tendo havido apenas três entrevistas com pais de alunos. Cabe ressaltar que a intenção não foi constituir uma amostra representativa do universo investigado, mas identificar as especificidades de cada contexto e analisar como se configuraram, dentro dele, as práticas sociais focalizadas. Todos esses procedimentos constaram no projeto previamente aprovado pelo Comitê de Ética em Pesquisa da Universidade Federal de Minas GeraisUFMG, e os entrevistados assinaram Termo de Consentimento Livre e Esclarecido para participação na pesquisa.

\section{Análise dos dados}

Os dados obtidos nessas duas etapas de investigação foram submetidos à análise de conteúdo baseada na leitura extensiva e intensiva, buscando extrair tópicos mais relevantes para discussão, bem como identificar linhas interpretativas que possibilitassem compreender a realidade social em questão. Os principais resultados obtidos são apresentados e discutidos a seguir.

\section{Resultados e Discussão}

\section{Dever de casa e relação família-escola:} concepções das famílias quanto ao dever de casa

Do ponto de vista da relação família-escola, os dados obtidos apontam, em primeiro lugar, para um consenso, entre as famílias de camadas médias e de camadas populares que participaram da pesquisa, em torno da importância do dever de casa, da necessidade de sua prescrição pela escola e de seu acompanhamento pelos pais. Embora, conforme atestam várias entrevistas, o acompanhamento aos deveres inclua, muitas vezes, situações de tensões e desgastes, a grande maioria dos entrevistados considera que isso "faz parte" de seu papel educativo. Eles defendem unanimemente a importância do dever de casa e argumentam que a família não pode deixar somente para a escola a responsabilidade pela aprendizagem dos filhos, devendo implicar-se com esse processo, inclusive apoiando a realização dos deveres.

As principais diferenças, no que tange às concepções familiares sobre o dever de casa, foram identificadas em relação a dois eixos. Em primeiro lugar, ao justificar a importância do dever de casa, as famílias de camadas populares enfatizaram principalmente a fixação do aprendizado que ele pode proporcionar, sendo que algumas mães também mencionaram o fato de o dever ocupar o tempo da criança de forma "útil", evitando que ela fique "solta" ou vá para a rua. Já nas camadas médias, houve argumentações mais diversificadas, as quais, ao lado da fixação do aprendizado e revisão dos conteúdos da aula (aspecto sempre recorrente), bem como da ocupação do tempo da criança com uma atividade "saudável, construtiva", destacaram também: o desenvolvimento do hábito de estudo; o desenvolvimento de atitudes de autonomia, compromisso e responsabilidade (idéia de que o dever é o "trabalho" da criança); a concepção de que o dever é um canal para a participação dos pais na vida escolar dos filhos, permitindo acompanhar o que estão estudando e verificar seu desenvolvimento; e a idéia de que o acompanhamento ao dever de casa proporciona um momento de vínculo e interação entre pais e filhos. 
Um segundo eixo de diferenciação entre as concepções familiares, identificado tanto entre as famílias de camadas populares quanto entre as de camadas médias, refere-se a questões secundárias em torno do dever de casa, como as formas e níveis de acompanhamento a ser feito, a quantidade adequada de dever de casa, dentre outros. Enfim, trata-se de situação semelhante à observada por Henriques (2007) em estudo de caso numa escola pública portuguesa: a autora constata que os deveres de casa (chamados TPC - trabalhos para casa) são consentidos pelos diferentes atores sociais, havendo quase unanimidade no reconhecimento de sua utilidade e discordância apenas no que se refere aos modelos de TPC praticados.

No caso brasileiro, esse consenso quanto à importância do dever de casa não se revela tão uniformemente em outras pesquisas, podendo ser problematizado de diversas formas (Resende, 2006). $\mathrm{Na}$ presente investigação, mostrou-se relevante interpretá-lo no contex to do que alguns autores, como De Queiroz (1995), Vincent, Lahire e Thin (2001) vêm apontando como a dominância, na sociedade atual, do modo escolar de socialização. Tal modo de socialização seria, segundo esses autores, inseparável da constituição da noção moderna de infância (Ariès, 1981), que implica em uma separação entre o mundo infantil e o mundo adulto, tornando-se as crianças objeto de ações educacionais específicas e a elas adaptadas. Assim, uma das características do modo de socialização escolar é o fato de se basear em relações pedagógicas impessoais entre um mestre e um aprendiz, por meio das quais se constroem formas próprias de organização do tempo e do espaço, voltadas especificamente para a educação. Ou seja, em oposição a um modo de socialização que se dá na prática, por imersão no mundo adulto e em suas dinâmicas, o modo de socialização escolar implica "retirar" a criança para espaços e tempos especialmente criados com o fim de "ensiná-la" ou de proporcionarlhe o desenvolvimento de conhecimentos, habilidades, valores.
Segundo Vincent e cols. (2001), o modo de socialização escolar, nas sociedades contemporâneas, estendeu-se e generalizou-se além das fronteiras da própria escola. Ele se manifestaria, dentre outras formas, na constante preocupação educativa dos adultos em relação às crianças, levando-os a transformar cada instante e cada atividade infantis em um instante de educação, uma atividade formativa.

Caracteriza-se, dessa forma, um contexto no qual, ao que parece, pode-se compreender melhor a valorização unânime, pelos pais, do dever de casa. Esta se explicaria, assim, não apenas pelo reconhecimento, por parte das famílias, da importância da escolarização na sociedade atual, ou pela persistência de uma tradição que vê no dever de casa um recurso de aprendizagem e de sucesso acadêmico ${ }^{1}$. Explicar-se-ia, também, e talvez principalmente, por um "transbordamento" da forma escolar para a sociedade, o qual suscitaria novos critérios para pensar a infância e a estruturação do seu tempo. Nesse sentido, a apologia dos deveres de casa estaria relacionada, em boa medida, ao fato de eles regularem, ordenarem e ocuparem uma parte do tempo da criança no lar, transformando-o em tempo "educativo". Não seria o caso, portanto, de uma adesão meramente utilitária ou instrumentalista a essa prática, mas de uma aceitação da mesma no quadro mais amplo da compreensão da infância segundo um determinado modo de socialização.

Dever de casa e relação família-escola: práticas familiares de acompanhamento aos deveres de casa

No que tange às práticas das famílias em relação ao dever de casa, as declarações contidas nos

\footnotetext{
${ }^{1} \mathrm{Se}$, por um lado, tal tradição tem sido reafirmada pela divulgação de pesquisas que associam a realização do dever de casa ao melhor desempenho acadêmico dos estudantes (Brasil, 2003; Franco e cols., 2007), por outro lado tal relação não está claramente estabelecida, sendo questionada por pesquisadores que apontam a dificuldade de estabelecer um nexo causal entre as duas variáveis (Glasman, 2005; Carvalho, 2006).
} 
questionários e nas entrevistas indicam que, na maioria dos casos, existe um investimento de tempo dos pais no acompanhamento aos deveres de casa dos filhos, com variações relativas a quem faz esse acompanhamento, qual o tempo investido e quais as modalidades de ajuda.

Confirmando dados de outras pesquisas (Franco, 2002), é a mãe quem acompanha com maior frequiência os deveres de casa dos filhos, nas três escolas investigadas. Nas respostas aos questionários, a porcentagem de famílias em que essa é uma tarefa materna chega a $86,5 \%$ na Escola Estrela, $82 \%$ na Lua e $61 \%$ na Sol.

Por um lado, esses dados colocam em relevo a discussão sobre as implicações de gênero das políticas de envolvimento parental na escolaridade dos filhos. Para Carvalho (2000), a ênfase na prescrição de deveres de casa e no seu acompanhamento pelos pais reforçaria as desigualdades na divisão do trabalho educativo no interior das famílias, ampliando os deveres domésticos das mães.

Por outro lado, os dados relativos à Escola Sol merecem atenção. Entre as três instituições investigadas, é na Sol que se observa a menor porcentagem de mães que fazem o acompanhamento aos deveres escolares dos filhos e, ao mesmo tempo, a maior porcentagem de pais que se responsabilizam por essa tarefa $(24 \%$, contra $20 \%$ na Escola Lua e $10 \%$ na Estrela). Além disso, destaca-se ainda, nessa escola, uma porcentagem significativa (18\%) de outras pessoas, além do pai e da mãe, que também ajudam no dever de casa (irmãos, tios, avós, madrinha, primos). O que se constatou nas entrevistas é que a explicação para tais dados encontra-se ligada às dificuldades enfrentadas, nas famílias desse meio social, no acompanhamento dos filhos: tanto dificuldades de tempo - por exemplo, no caso das mães que são empregadas domésticas e enfrentam longas jornadas diárias de trabalho -, quanto obstáculos ligados à baixa escolaridade. Nesse contexto, assume a tarefa de acompanhamento a pessoa que tem mais condições de fazê-lo, seja a mãe, o pai, um irmão, uma tia, recorrendo-se também a outros parentes, vizinhos e colegas da própria criança.

Esse recurso a parentes, vizinhos, conhecidos, com o fim de suprir necessidades de auxílio nos deveres, foi identificado como uma prática recorrente nas famílias de camadas populares investigadas e também em estudos como o de Nogueira e Abreu (2004). Constitui, para esses autores, uma estratégia de mobilização familiar que confirma a importância atribuída pelas famílias desse meio social à escolarização dos filhos. Observa-se que tal estratégia chega, em vários casos, a subverter a divisão tradicional de trabalho educativo que coloca a mulher como principal responsável pelo acompanhamento à vida escolar da prole.

Quanto ao tempo investido pelas famílias no acompanhamento aos deveres, a maior parte das respostas ao questionário o situa em torno de 30 minutos diários, considerando o tempo total em que o adulto se mantém disponível para a ajuda e não necessariamente tempo de auxílio efetivo. Há, entretanto, algumas famílias, especialmente nas escolas Estrela e Lua, em que esse tempo é de mais de uma hora, bem como outras em que não chega a 15 minutos. A compreensão dessa variabilidade é complexa, envolvendo fatores como o tipo e a quantidade de dever, o perfil do aluno e seu ritmo de trabalho, o tipo de ajuda oferecida, dentre outros. Como afirma Glasman (2005) em relação ao tempo gasto pela criança com o dever de casa, é pouco provável, nesse caso, encontrar uma medida precisa, com base apenas em declarações dos envolvidos.

Mais relevante para a compreensão das práticas familiares de acompanhamento aos deveres é considerar o tipo de ajuda oferecida à criança. Nesse caso, verifica-se uma diferença significativa entre as escolas privadas e a pública, considerando as respostas aos questionários e também as entrevistas. Nas escolas privadas, as tarefas que os pais afirmam exercer com maior freqüência indicam um papel, exercido pelos adultos, de apoio e suporte à atividade do filho: ajudar a criança na busca de informações em 
livros, revistas, enciclopédias, internet, dentre outros; fornecer materiais de consulta e de apoio; esclarecer dúvidas sobre o enunciado das questões; revisar o dever depois de pronto e sugerir correções. Na maior parte dos casos, nesse meio social, os entrevistados afirmam que as crianças já têm certa autonomia para a realização das atividades, demonstrando a internalização de hábitos e disposições em relação ao dever de casa.

Já na escola Sol, a situação se inverte. Embora a tarefa mais freqüente no acompanhamento aos deveres seja a mesma dos colégios Estrela e Lua ajudar a criança na busca de informações em diferentes veículos -, são freqüentemente citadas tarefas pouco assinaladas nos colégios privados, tais como lembrar a criança do dever e assegurar que o faça, verificar se os deveres estão completos, exigir capricho e organização no trabalho. Considera-se que essa diferença pode estar relacionada tanto a uma menor internalização do hábito de fazer o dever de casa entre as crianças da Escola Sol, que se manifesta no alto índice daquelas que freqüentemente deixam de cumprir as tarefas, quanto ao baixo nível de escolaridade dos pais, que dificultaria a execução de tarefas como "esclarecer dúvidas sobre o enunciado das questões".

Torna-se importante, sobretudo, destacar que, na Escola Sol, as tarefas mais freqüentes no acompanhamento ao dever parecem configurar um papel de cobrança e disciplinamento exercido pelo adulto, coerente com um modo de autoridade apontado por alguns estudos (Nogueira \& Abreu, 2004; Thin, 1998) como típico das camadas populares, o qual seria baseado no controle exterior, mais do que na internalização de regras e disposições.

Outro aspecto explorado tanto nos questionários quanto nas entrevistas foi o procedimento mais comumente adotado pelos pais quando a criança tem dúvidas na realização do dever. Na análise dos questionários, destacou-se a porcentagem significativa (na faixa dos 40 a 50\%), nas três escolas, de mães e pais que ajudam diretamente o filho a fazer a atividade, avisando ou não à professora. Constata-se, nesse caso, que tais famílias assumem uma tarefa estritamente pedagógica, dispondo-se a ensinar um conteúdo escolar às crianças. Há, ainda, uma parcela significativa de entrevistados que, na mesma situação, orientam a criança a tentar fazer a questão e conferir com a professora (41\% na escola Estrela, 34\% na Lua e $28 \%$ na Sol). Esse procedimento pode ser indicativo de certa tendência a uma maior divisão de papéis entre família e escola, remetendo a esta a responsabilidade pelo ensino em si. Também é digna de nota, no caso, a porcentagem relativamente elevada (19\%) de famílias da escola Sol que orientam as crianças a deixar a questão em branco, havendo certamente, aí, além da concepção sobre a divisão do trabalho entre escola e família, a influência da baixa escolaridade dos pais e mães.

Nas entrevistas, o que se identificou foi uma tendência, comum à maioria dos pais, de auxiliarem a criança, caso tenham as condições para isso: "se eu sei e posso ensinar pro meu filho, por que vou esperar a professora e deixá-lo com dúvida?" (mãe de um aluno da Escola Lua). Em conformidade com estudos como o de Ribeiro e Andrade (2006), constatou-se também que, nas famílias de camadas populares, boa parte dos desgastes gerados pelo dever de casa advém do fato de se desejar oferecer esse auxílio, sem que se consiga fazê-lo, em função das deficiências da própria escolarização. Nesse contexto, além do já mencionado recurso a uma rede de parentes e vizinhos, algumas famílias mobilizavam-se também para incluir os filhos em projetos que oferecem apoio, fora do horário regular de aulas, para a realização dos deveres, desenvolvidos seja pela própria Escola Sol, seja por Organizações Não Governamentais (ONGs) e entidades filantrópicas.

Diversas outras estratégias de apoio à escolaridade dos filhos, para além da ajuda específica nos deveres, foram identificadas tanto em famílias de camadas médias quanto em famílias de camadas populares: tomar a tabuada, incentivar a leitura, propor exercícios complementares, dentre outras. A respeito desse aspecto, chamaram a atenção, por um lado, as diferenças internas aos dois grupos (havendo, em 
cada um deles, algumas famílias mais fortemente mobilizadas que outras do mesmo grupo) e, por outro, as desigualdades existentes entre eles quanto às condições de proporcionar esse apoio.

\section{Dever de casa e relação família-escola: consonâncias e dissonâncias}

Apesar do consenso constatado em relação à importância dos deveres de casa e das estratégias de mobilização identificadas entre as famílias, observaram-se, também, significativas variações na relação estabelecida com a prática de realização e acompanhamento dos deveres. Enquanto, para algumas famílias, esse é um processo tranqüilo e até mesmo prazeroso, para outras é vivido com tensões e desgastes. Algumas vezes, essa variação é identificada não apenas entre duas famílias, mas dentro de uma mesma, em relação a dois filhos diferentes. Trata-se de uma relação que depende do perfil de cada criança, de suas facilidades ou dificuldades diante dos deveres, do tipo de dever proposto pela escola, do perfil do adulto que está acompanhando, da relação desse adulto com o conhecimento e com a cultura escolar. Além disso, mostrou-se pertinente, também nesse caso, a discussão em torno da noção de modo de socialização escolar, a qual pode proporcionar subsídios para a compreensão das dificuldades e conflitos vividos na relação das crianças e das famílias com o dever de casa e, por meio dele, com a própria escolarização.

$\mathrm{Na}$ linha do que vem sendo discutido por autores como Lahire (1997) e Thin (1998, 2006), as questões relativas ao dever de casa podem ser analisadas a partir da idéia de consonância ou dissonância entre os modos de socialização escolar e familiar. Na origem de dificuldades como a não-realização dos deveres (muito freqüente na Escola Sol) ou os desgastes entre pais e filhos para assegurar o seu cumprimento, constata-se muitas vezes, dentre outros motivos, a dissonância entre os referidos modos de socialização, a qual pode se manifestar em relação a aspectos diversificados, tais como: o modo de autoridade familiar e a forma das relações estabelecidas entre adulto e crianças; os modos de organização do tempo e do espaço; a centralidade do uso da linguagem escrita no ambiente familiar, ou não; a prevalência de uma relação mais prática ou mais objetivada com os saberes e fazeres; dentre outros. Todos esses são aspectos que de alguma forma se relacionam com o cumprimento dos deveres de casa.

Em concordância com estudos como os de Lahire (1997), os dados levantados na pesquisa parecem sinalizar que, ao se investigar, a partir da questão do dever de casa, as dissonâncias e consonâncias entre os processos socializadores familiares e escolares, torna-se necessário ir além da categoria classe social e analisar as configurações singulares de fatores ou traços que podem compor diferentes perfis familiares dentro de uma mesma classe. Assim, apesar de, no seu conjunto, as famílias de camadas populares tenderem a seguir lógicas socializadoras que, em vários aspectos, se opõem às lógicas escolares (Thin, 2006), observaram-se, nesse meio social, algumas famílias que, nas entrevistas, pareciam sinalizar traços favorecedores de maior adesão dos filhos às exigências do mundo escolar. É o caso, por exemplo, de famílias que valorizam de forma especial, dentro das suas possibilidades, a cultura escrita ou a própria cultura escolar.

Enquanto isso, nas camadas médias, que em seu conjunto tenderiam a vivenciar padrões de socialização mais próximos aos escolares (Nogueira, 1991), encontraram-se também distintos perfis familiares, alguns com traços que pareciam entrar em conflito com os valores escolares, tais como a orientação mais lúdica do que ascética, a valorização dos saberes práticos sobre os conhecimentos abstratos, a pequena frequiência de práticas de leitura e de escrita entre os próprios pais.

Ou seja, embora, no plano do discurso, tenhase observado um consenso, na população investigada, em torno da importância do dever de casa e de seu acompanhamento pelas famílias, verificou-se também, tanto no grupo de famílias de camadas médias quanto no de camadas populares, a desigualdade de condições para esse acompanhamento. Trata-se, aqui, de desigualdades não apenas no que se refere a 
condições materiais ou a condições simbólicas mais explícitas - como as relativas ao capital cultural, evidentes nas diferenças de nível de escolaridade entre os pais participantes dos dois grupos da pesquisa -, mas também no que tange a aspectos mais difusos, como as práticas e os valores constituidores do processo de socialização.

\section{Dever de casa e currículo escolar: concep- ções e práticas no âmbito da escola}

Transitando do âmbito das famílias para o das escolas e seus currículos, outro achado relevante da pesquisa - em geral silenciado nos estudos existentes (Carvalho, Nascimento, \& Paiva, 2006) - é a desigualdade que deriva das próprias práticas curriculares de diferentes instituições. Nas observações em sala de aula, constatou-se, nas turmas de camadas médias, maior adesão dos alunos às práticas em torno do dever de casa. O número de crianças que não faziam o dever ou o faziam de modo incompleto era sempre bastante baixo nessas turmas e muito alto nas turmas da escola pública. O que se verificou é que para se compreender essa diferença precisa ser considerado, dentre outros fatores, o próprio modo como cada escola trabalha com o dever de casa, no âmbito do currículo em ação - modo esse que, por sua vez, relaciona-se com a proposta pedagógica da instituição.

De fato, nas Escolas Lua e Estrela constatouse toda uma política de valorização do dever de casa, envolvendo desde as concepções dos profissionais (dever de casa como situação de estudo que deve ser estimulante e enriquecedora) até as práticas em torno do dever. Tais práticas incluem a existência de orientações sobre os deveres de casa, para as famílias e para os alunos, em documentos da escola; o modo como é proposto (com negociações, explicações, incentivos); o lugar importante que ocupa nas aulas (empregando-se um significativo tempo diário na discussão das questões); o tipo de atividade que o compõe (valorizando a auto-expressão, o desafio, a criatividade); a forma participativa de discuti-lo em sala. Tal política, por sua vez, reflete projetos pedagógicos e curriculares que, embora diferentes nas duas escolas, têm em comum o fato de estimular metodologias participativas, baseadas na idéia do aluno como sujeito ativo de seu processo de aprendizagem e na busca de um conhecimento contextualizado e significativo para a criança.

Já na Escola Sol, o dever é concebido e tratado como uma "obrigação" do aluno, algo que ele precisa "cumprir" para "ir pra série seguinte". Não é objeto de uma política explícita da instituição, inexistindo referência a ele nos documentos escolares. Segundo a coordenadora entrevistada, há uma regra informal de que "todos os dias a criança deve ter dever"; porém, no cotidiano das turmas, isso nem sempre acontece. Por fim, o dever de casa é implicitamente desvalorizado na própria dinâmica das aulas, uma vez que raramente é colocado em discussão, privilegia atividades de repetição e é corrigido de forma pouco participativa. Algumas vezes, o dever sequer é retomado pela professora, ou seja, ela não faz qualquer tipo de verificação, correção ou discussão da atividade realizada pelos alunos. Tal tratamento dado ao dever, por sua vez, realiza-se no contexto de uma prática pedagógica centralizada na figura do professor e na expectativa de "obediência" do aluno. Este, visto freqüentemente sob a ótica de supostos déficits - seus ou da família - , é tratado de modo coercitivo, em uma perspectiva de disciplinamento, restando-lhe manifestar formas de resistência ou de indiferença aos valores escolares (Perrenoud, 1995).

Em síntese, os dados obtidos quanto às práticas curriculares ligadas ao dever de casa nas três escolas investigadas indicam que, somando-se às desigualdades no âmbito das famílias, e interagindo com elas, existem também desigualdades significativas entre as ofertas escolares dos três estabelecimentos, as quais desfavorecem os mais desfavorecidos (Dubet, 2004). Nesse sentido, o dever de casa espelha, aqui, o fato de que a escola não apenas registra ou reproduz as desigualdades já existentes na sociedade, mas pode também alimentá-las com novos elementos de exclusão, através de seus modos de funcionamento, os quais podem exercer efeitos 
específicos na trajetória escolar e nas experiências dos indivíduos (Dubet, 2003).

Evidentemente, tais efeitos não podem, por um lado, ser analisados adequadamente sem contextualizá-los na discussão das políticas públicas educacionais, das condições de formação e atuação docente e de funcionamento das escolas. Por outro lado, se eles dependem de todas essas questões macroestruturais, dependem também, em alguma medida, do projeto pedagógico da instituição e das concepções educacionais assumidas pelos educadores (Duru-Bellat \& Van Zanten, 1999).

Nesta pesquisa, as práticas pedagógicas analisadas eram referentes a escolas de realidades socioeconômicas confrontantes e de diferentes sistemas de ensino (público e privado), o que pode levar a uma prevalência dos aspectos macroestruturais na explicação das diferenças constatadas. Entretanto, Carvalho e cols. (2006) apresentam uma interessante comparação entre quatro práticas pedagógicas ligadas ao dever de casa, todas em escolas públicas de João Pessoa-PB, evidenciando diferenças entre elas quanto a seu potencial de se tornarem significativas para os alunos e efetivas em termos de aprendizagem. Em dois casos, a prática do dever de casa era sistemática e tinha lugar privilegiado em sala de aula, sendo bem articulada ao planejamento pedagógico como um todo. Em outras duas escolas, o dever se restringia a um ritual mal articulado ao processo ensino-aprendizagem ou a um mecanismo de compensação da baixa produtividade da aula. Tais resultados, consoantes com os obtidos na presente pesquisa, confirmam a importância das concepções e dos projetos educacionais assumidos pelos educadores na construção do efeito específico que suas práticas podem exercer.

\section{Considerações finais}

A julgar pela raridade de sua presença nas pesquisas acadêmicas e mesmo na literatura do campo educacional, poder-se-ia considerar o dever de casa como um aspecto periférico do processo escolar, uma espécie de complemento a respeito do qual não haveria muito que discutir ou investigar. Pesquisas atuais, já mencionadas neste trabalho, vêm apontando a realização desse tipo de atividade como um dos fatores da proficiência escolar. Nessa medida, o dever de casa passa a ser considerado, também, como variável do processo educacional, mas ainda não satisfatoriamente tomado como objeto, em si, de investigação.

Neste trabalho, buscou-se incidir sobre essa lacuna, verificada de modo especial no campo da pesquisa sociológica em educação, tomando o dever de casa como objeto de estudo. Utilizando-o como um espelho, procurou-se vislumbrar reflexos, tanto das relações que famílias de diferentes meios sociais estabelecem com o processo de escolarização, na sociedade atual, quanto dos processos de constituição do chamado currículo em ação, no contexto escolar.

Olhando para esse espelho do dever de casa, foi possível vislumbrar como famílias de diferentes meios sociais dão importância à escolarização de sua prole e parecem se comprometer com ela, mas detêm recursos materiais e simbólicos desiguais para fazer frente às exigências desse processo. Constatou-se a diversidade de estratégias escolares de que essas famílias lançam mão. Verificou-se que na prática escolar do dever de casa sintetizam-se dissonâncias e consonâncias entre os modos familiar e escolar de socialização. É importante frisar que não se está tomando o conjunto de famílias efetivamente envolvidas na pesquisa como, necessariamente, representativo do universo do qual faz parte.

Foi também possível, ao olhar para esse espelho, discutir o papel que diferentes práticas pedagógicas podem exercer na construção das trajetórias escolares e da relação com a escola e o conhecimento, sabendo-se ser este um aspecto freqüentemente secundarizado nos estudos da relação família-escola. Pôde-se, ainda, antever o modo como a política do dever de casa reflete e se insere em processos mais amplos de configuração curricular, revelando, no âmbito microssociológico do currículo em ação, relações que articulam processos micro e macrossociais, chegando à própria relação entre escola e estruturas sociais. 
Diante das questões apresentadas, parece evidenciar-se a complexidade escondida sob as práticas aparentemente banais ligadas ao dever de casa. Refletidos nessas práticas, revelam-se distintos processos, distintas lógicas e concepções escolares e familiares, que se entrecruzam de variadas formas e ganham diferentes sentidos em cada contexto educacional específico. Dessa forma, parece justificarse, do ponto de vista científico, uma mirada mais atenta a esse espelho e a suas revelações.

\section{Referências}

Almeida, A. M. F., \& Nogueira, M. A. (2002). A escolarização das elites: Um panorama internacional da pesquisa. Petrópolis, RJ: Vozes.

Alves-Mazzotti, A. J., \& Gewandsznajder, F. (1998). O método nas ciências naturais e sociais: Pesquisa quantitativa e qualitativa. São Paulo: Pioneira.

Ariès, P. (1981). História social da criança e da família (2a ed.). Rio de Janeiro: LTC.

Bourdieu, P. (1998). Os três estados do capital cultural. In M. A. Nogueira \& A. Catani (Orgs.), Escritos de educação (pp.70-79). Petrópolis, RJ: Vozes.

Brasil. Ministério da Educação. Instituto Nacional de Estudos e Pesquisas Educacionais. (2003). Lição de casa é um dos fatores de maior impacto no rendimento dos alunos. Recuperado em 11 julho 2003, de http://www.inep.gov.br/imprensa/noticias/saeb/news03_07.htm.

Carvalho, M. E. P. (2000). Relações entre família e escola e suas implicações de gênero. Cadernos de Pesquisa, 110, 143-155.

Carvalho, M. E. P. (2001). Rethinking family-school relations: A critique of parental involvement in schooling. Mahwah, NJ: Lawrence Erlbaum.

Carvalho, M. E. P. (2004). Escola como extensão da família ou família como extensão da escola? O dever de casa e as relações família-escola. Revista Brasileira de Educação, 25, 94-104.
Carvalho, M. E. P. (2006). O dever de casa como política educacional e objecto de pesquisa. Revista Lusófona de Educação, 8, 875-102. Recuperado em 03 julho 2007, de http://rleducacao.ulusofona.pt/ pdf08/artigos_maria_carvalho.pdf

Carvalho, M. E. P.; Nascimento, C. S., \& Paiva, C. M. (2006). O lugar do dever de casa na sala de aula. Olhar de Professor, 9(2), 341-357. Recuperado em 18 abril 2007, de www.uepg.br/ olhardeprofessor/pdf/revista92_artigo09.pdf.

De Queiroz, J. M. (1981). La désorientation scolaire: Sur le rapport social des familles populaires urbaines à la scolarisation. Thèse (III cycle) non publiée, Université Paris VIII, Paris.

De Queiroz, J. M. (1995). L'école et sés sociologies. Paris: Nathan.

Dubet, F. (2003). A escola e a exclusão. Cadernos de Pesquisa, 119, 29-45.

Dubet, F. (2004). O que é uma escola justa? Cadernos de Pesquisa, 123, 539-555.

Duru-Bellat, M., \& Van Zanten, A. (1999). Sociologie de l'école. Paris: Armand Colin.

Franco, C., Ortigão, M. I., Albernaz, A., Bonamino, A., Aguiar, G., Alves, F., \& Satyro, N. (2007). Qualidade e eqüidade em educação: Reconsiderando o significado de "fatores intra-escolares". Recuperado em 03 julho 2007, de http://www.econ.puc-rio.br/PDF/seminario/2007.

Franco, O. C. M. (2002). Práticas familiares em relação ao dever de casa: Um estudo junto às camadas médias de Belo Horizonte. Dissertação de mestrado não-publicada, Universidade Federal de Minas Gerais, Belo Horizonte, MG.

Glasman, D. (2005). Le travail des élèves pour l'école en dehors de l'école. Chambery: Université de Savoie.

Henriques, M. E. F. (2007). Os trabalhos de casa na escola do $1^{\circ}$ ciclo da Luz: Estudo de caso. In P. Silva (Org.), Escolas, famílias e lares: Um caleidoscópio de olhares (pp. 211-230). Porto: Profedições. 
Lahire, B. (1997). Sucesso escolar nos meios populares: As razões do improvável. São Paulo: Ática.

Moreira, A. F., \& Silva, T. T. (Orgs.). (1999). Currículo, cultura e sociedade (3a ed.). São Paulo: Cortez.

Moreira, A. F. B. (2001). O campo do currículo no Brasil: Os anos noventa. Currículo sem fronteiras, 1(1), 35-49. Recuperado em 02 maio 2007, de http://www.curriculosemfronteiras.org

Nogueira, M. A. (1991). Trajetórias escolares, estratégias culturais e classes sociais: Notas em vista da construção do objeto de pesquisa. Teoria \& Educação, 3, 89-112.

Nogueira, M. A. (1995). Famílias de camadas médias e a escola: Bases preliminares para um objeto em construção. Educação e Realidade, 20(1), 9-25.

Nogueira, M. A. (1998). Relação família-escola: Novo objeto na sociologia da educação. Paidéia (Ribeirão Preto), 8, 91-103.

Nogueira, M. A., \& Abreu, R. C. (2004). Escola pública e famílias populares: Uma relação dissonante. Educação em Revista, 39, 41-60.

Nogueira, M. A., \& Nogueira, C. M. M. (2004). Bourdieu \& a educação. Belo Horizonte: Autêntica.

Nogueira, M. A., Romanelli, G., \& Zago, N. (Orgs.). (2000). Família e escola: Trajetórias de escolarização em camadas médias e populares. Petrópolis, RJ: Vozes.

Pastore, J., \& Silva, N. V. (2000). Mobilidade social no Brasil. São Paulo: Makron Books.

Paula, F. A. (2000). Lições, deveres, tarefas, para casa: Velhas e novas prescrições para professoras. Dissertação de mestrado nãopublicada, Universidade Estadual de Campinas, Campinas, SP.

Perrenoud, P. (1995). Ofício de aluno e sentido do trabalho escolar. Lisboa: Porto.
Quadros, W. (1991). O milagre brasileiro e a expansão da nova classe média. Tese de doutorado não-publicada, Universidade Estadual de Campinas, Campinas, SP.

Resende, T. F. (2006). Dever de casa: Questões em torno de um consenso. Reunião Anual da Associação Nacional de Pós-Graduação e Pesquisa em Educação, 29. Recuperado em 01 julho 2007, de http://www.anped.org.br.

Ribeiro, D. F., \& Andrade, A. S. A. (2006). Assimetria na relação entre família e escola pública. Paidéia (Ribeirão Preto), 16, 385-394.

Setton, M. G. J. (2005). Um novo capital cultural: Prédisposições e disposições à cultura informal nos segmentos com baixa escolaridade. Educação \& Sociedade, 26. Recuperado em 05 agosto 2007, de http://www.scielo.br/pdf/es/v26n290/ a04v2690.pdf

Thin, D. (1998). Quartiers populaires: L'école et les familles. Lyon: Presses Universitaires de Lyon.

Thin, D. (2006). Para uma análise das relações entre famílias populares e escola: Confrontação entre lógicas socializadoras. Revista Brasileira de Educação, 11, 211-225.

Vincent, G., Lahire, B., \& Thin, D. (2001). Sobre a história e a teoria da forma escolar. Educação em Revista, 33, 7-47.

Artigo recebido em 15/11/2007.

Aceito para publicação em 08/08/2008.

A presente pesquisa vincula-se ao Projeto Integrado de Pesquisa do Observatório Sociológico Família-Escola da Faculdade de Educação da Universidade Federal de Minas Gerais. Apoio: CNPq e FAPEMIG. O projeto específico deste trabalho foi financiado pela Pró-reitoria de Pesquisa da UFMG, através do Programa de Auxílio para a Pesquisa dos Recém-Doutores 
Endereço para correspondência:

Profa. Dra. Tânia de Freitas Resende. Universidade Federal de Minas Gerais. Faculdade de Educação. Departamento de Ciências Aplicadas à Educação. Campus Pampulha. Av. Antônio Carlos, 6627. CEP 31270-90. Belo Horizonte-MG, Brasil. E-mail: taniaresende@fae.ufmg.br

Tânia de Freitas Resende é Professor Adjunto da Faculdade de Educação da Universidade Federal de Minas Gerais. 